\title{
Heterogeneous Fenton-like degradation of Rhodamine 6G in water using CuFeZSM-5 zeolite catalyst prepared by hydrothermal synthesis
}

\author{
M. Dükkancı ${ }^{a}$, G. Gündüz ${ }^{\mathrm{a}, *}$, S. Yılmaz ${ }^{\mathrm{b}}$, R.V. Prihod'koc ${ }^{\mathrm{c}}$ \\ a Ege University, Chemical Engineering Department, 35100 Bornova, Izmir, Turkey \\ b Izmir Institute of Technology, Chemical Engineering Department, Gülbahçe Village, 35437 Urla, Izmir, Turkey \\ ${ }^{c}$ Dumanski Institute of Colloid and Water Chemistry, National Academy of Sciences of Ukraine, 03680 Kiev-142, blv. Vernadskogo 42, Kiev, Ukraine
}

\section{A R T I C L E I N F O}

\section{Article history:}

Received 19 January 2010

Received in revised form 19 April 2010

Accepted 4 May 2010

Available online 11 May 2010

\section{Keywords:}

CuFeZSM-5 zeolite

FeZSM-5 zeolite

Rhodamine 6G

Heterogeneous Fenton-like degradation

\begin{abstract}
A B S T R A C T
In this study, heterogeneous Fenton-like degradation of reactive azo dye Rhodamine 6G in water was investigated over a CuFeZSM-5 zeolite catalyst prepared by hydrothermal synthesis. At initial $\mathrm{pH}$ of 3.4 , a color removal of $100 \%$ was achieved after a reaction time of $45 \mathrm{~min}$. TOC elimination was measured to be $51.8 \%$ after $2 \mathrm{~h}$ of oxidation. Initial decolorization rate was described by an equation of $-r_{\mathrm{A} 0}=$ $4.56 \times 10^{2} e^{-24.83 / R T} C_{\mathrm{RGG}, 0} C_{\mathrm{H}_{2} \mathrm{O}_{2}, 0}^{0.35}$ where $R$ is in $\mathrm{kJ} / \mathrm{mol}$. The leaching of iron and copper cations from zeolite structure into the solution during oxidation was dependent on $\mathrm{pH}$ strongly. The regulation of $\mathrm{pH}$ from 6.5 (dye solution $\mathrm{pH}$ ) to 3.4 , increased leaching for iron from 0.7 to $0.8 \mathrm{mg} / \mathrm{dm}^{3}$ and for copper from 1.4 to $2.1 \mathrm{mg} / \mathrm{dm}^{3}$. The copper was totally leached from the catalyst during the process at $\mathrm{pH} 3.4$.
\end{abstract}

(c) 2010 Elsevier B.V. All rights reserved.

\section{Introduction}

Large quantities of waste water are discharged into the environment during the textile dyeing process. These effluents are intensely colored and contaminated with high concentrations of chemical oxygen demand. They not only deteriorate the aesthetics of receiving waters, but also pose significant threat to aquatic life because of the hindrance of the penetration of oxygen and formation of some toxic products by hydrolysis of dyes in the waste water.

Most of textile dyes are designed to produce long-lasting colors and are resistant to mild oxidation conditions. Therefore, stronger oxidation agents such as Fenton's reagent are needed to degrade these structures.

The Fenton-like processes are used as a powerful source of hydroxyl radicals from $\mathrm{H}_{2} \mathrm{O}_{2}$ in the presence of transitional metal cations, such as iron, $\mathrm{Fe}^{2+} / \mathrm{Fe}^{3+} / \mathrm{H}_{2} \mathrm{O}_{2}$, to decompose many organic compounds including dyes. However, the usage of homogeneous Fenton process has a number of disadvantages such as impossible regeneration of catalyst, requirement of narrow range of $\mathrm{pH}$ values for reaction and necessity of the treatment of the sludge containing iron before discharging it to receiving waters. These drawbacks can be overcome by using heterogeneous Fenton-type catalysts,

\footnotetext{
* Corresponding author. Tel.: +90 2323884000/2292; fax: +90 2323887776 .

E-mail address: gonul.gunduz@ege.edu.tr (G. Gündüz).
}

in particular, zeolites, whose recovery from water is not difficult. Iron and copper containing zeolites show redox properties because these metals can change their oxidation states [1-14]. Recently, high catalytic activity of iron containing zeolites for phenol oxidation $[15,16]$ and for degradation of dyes $[2,3]$ has been reported. Supported Fe-saponite clay catalysts revealed to be quite active in the Fenton-like oxidation of Orange II [4]. FeZSM-5 prepared by ion-exchange was tested in wet oxidation with hydrogen peroxide of diluted formic, acetic and propionic acid [17].

In literature it was reported that copper containing catalysts such as $\mathrm{Al}-\mathrm{Cu}$ catalyst supported on pillared clay and $\mathrm{CuO}$ catalyst supported on $\gamma-\mathrm{Al}_{2} \mathrm{O}_{3}$ showed high catalytic activity during oxidation of phenol dissolved in water [18] and isolated $\mathrm{Cu}^{2+}$ sites grafted to Al-MCM-41 also gave relatively high catalytic activity in ethane oxidation [19]. On the other hand, it is well known that copper exchanged zeolites such as CuZSM- 5 have been widely studied for selective catalytic reduction of $\mathrm{NO}_{\mathrm{x}}$ to $\mathrm{N}_{2}$ with ammonia or propane [20-22].

Although many studies were present in literature on wet peroxidative removal of textile dyes on Fe-containing zeolites, no study has been reported on iron and copper containing zeolites for heterogeneous Fenton-like degradation of textile dyes.

The aim of this paper is to assess the catalytic performances of iron and copper containing ZSM-5 zeolites prepared by hydrothermal synthesis on the Fenton-like degradation of Rhodamine $6 \mathrm{G}$, which is an important reactive azo dye used in textile industry. 
(a)

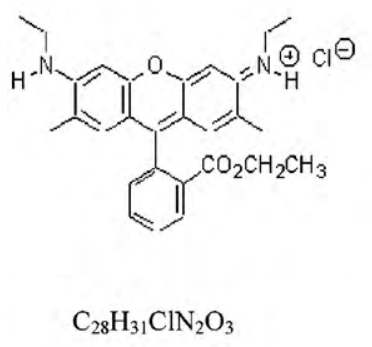

$(\mathrm{Mw}=479 \mathrm{~g} / \mathrm{mol})$

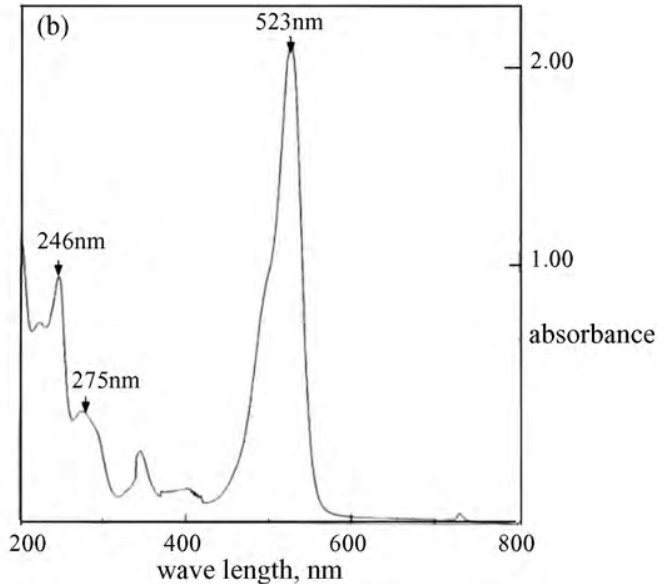

Fig. 1. Chemical structure of Rhodamine 6G (R6G) (a) and UV-vis. Absorption spectra of aqueous solutions of Rhodamine 6G (b).

\section{Experimental}

\subsection{Materials}

The reactive azo dye Rhodamine $6 G$ was obtained from Sigma-Aldrich and used without further purification. The absorption spectra of Rhodamine $6 \mathrm{G}$ is characterized by three main bands, one in the visible region $\left(\lambda_{\max }=523 \mathrm{~nm}\right)$ which is responsible for the chromophoric components (for the color of dye arising from aromatic rings connected by azo groups) and the others in the UV region $\left(\lambda_{\max }=246 \mathrm{~nm}\right.$ and $\left.\lambda_{\max }=275 \mathrm{~nm}\right)$ which represent the absorption of benzene-like and naphthalene-like structures in the molecule, respectively [4]. Rhodamine 6G is also called as R6G, Rh6G, C.I. Pigment Red 81, C.I. Pigment Red 169, C.I. 45160 where C.I. is color index. The hydrogen peroxide solution (35\%) of analytical grade was obtained from Merck. Aqueous solutions containing $0.1 \mathrm{~g} / \mathrm{dm}^{3}$ azo dye were prepared with deionized water from a Millipore Direct $Q$ purification unit.

Fig. 1 presents the chemical structure of Rhodamine 6G (R6G) (a) and UV-vis absorption spectra of aqueous solutions of Rhodamine $6 \mathrm{G}(\mathrm{b})$.

\subsection{Catalysts}

Hydrothermal synthesis method given by Szostak et al. [23] was applied to prepare FeZSM-5 sample. The same method was used for CuFeZSM-5. The prepared catalysts were characterized by nitrogen adsorption, XRD, SEM and FTIR measurements. The precise procedures for preparation and characterization of the catalysts were described in Ref. [24]. Metal contents and Si/Fe ratios of the catalysts were determined by ICP-AES method. BETsurface area $\left(S_{\mathrm{BET}}\right)$, total pore volume $\left(V_{\mathrm{p}}\right)$, average pore diameter $\left(d_{\text {ave }}\right)$ and chemical composition of CuFeZSM-5 and FeZSM-5 catalysts are given in Table 1 . CuFeZSM-5 catalyst contains $1.7 \%$ iron and about $0.2 \%$ copper. Iron content of FeZSM- 5 catalyst is about $2.5 \%$.

\subsection{Heterogeneous Fenton-like degradation}

Heterogeneous Fenton-like degradation of Rhodamine 6G (R6G) was performed under isothermal conditions in a temperaturecontrolled shaded glass batch reactor equipped with a mechanic stirrer and a pH electrode. In a typical run, $0.15 \mathrm{dm}^{3}$ of aqueous dye solution ( $0.1 \mathrm{~g}$-dye $/ \mathrm{dm}^{3}$-soln.) was placed into the reactor and the temperature was adjusted to $323 \mathrm{~K}$. When the temperature reached to $323 \mathrm{~K}, \mathrm{pH}$ of the solution was measured and $0.15 \mathrm{~g}$ of catalyst ( $1 \mathrm{~g}$-cat $/ \mathrm{dm}^{3}$-soln.) was introduced into the solution under continuous stirring. After stabilization of the temperature at $323 \mathrm{~K}, \mathrm{pH}$ of the solution was again measured and the solution was analyzed in order to determine whether the dye is adsorbed by the catalyst. Then a solution of $35 \% \mathrm{H}_{2} \mathrm{O}_{2}\left(40 \mathrm{mmol} \mathrm{H}_{2} \mathrm{O}_{2} / 0.15 \mathrm{dm}^{3}\right.$ solution, the amount of $\mathrm{H}_{2} \mathrm{O}_{2}$ used was in excess, which was equal to 1.34 times of the $\mathrm{H}_{2} \mathrm{O}_{2}$ amount necessary to completely oxidize dye to $\mathrm{CO}_{2}$ and $\mathrm{H}_{2} \mathrm{O}$ ) was added into the dye solution. After the addition of $\mathrm{H}_{2} \mathrm{O}_{2}$, $\mathrm{pH}$ of the solution was again measured ( $\mathrm{pH} \mathrm{6.1).} \mathrm{This} \mathrm{time} \mathrm{was}$ recorded as the starting time of the reaction. For the experiments with initial $\mathrm{pH}$ of 3.4, $\mathrm{pH}$ was regulated by addition of $\mathrm{H}_{2} \mathrm{SO}_{4}$ into the dye solution. The samples taken periodically at every 15 min were diluted in 1:10 ratio. After centrifugation for $0.5 \mathrm{~h}$ to remove the catalyst, the samples were analyzed with UV spectrophotometer (Jasco 7800 UV/Vis).

The decrease of the intensity of the band at $523 \mathrm{~nm}$ was used as a measure of decolorization degree. The absorbance peak at $275 \mathrm{~nm}$ is due to the naphthalene ring of R6G and the decrease of the intensity of this band was taken as a measure of degradation degree. The decrease in the intensity of the band at $275 \mathrm{~nm}$ is attributed to the formation of intermediates resulting from the degradation of the azo dye, which still contain benzoic and naphthalene type rings [17].

In addition to these measurements, total organic carbon (TOC) removal was determined using a TOC Shimadzu Vcph spectrophotometer for each run after a reaction time of $2 \mathrm{~h}$ for the evaluation of the mineralization of R6G dye. TOC was calculated as the difference between the total carbon (TC) and inorganic carbon (IC) in the liquid sample.

Table 1

Surface characteristics and physicochemical properties of FeZSM-5 and CuFeZSM-5 catalysts.

\begin{tabular}{|c|c|c|c|c|c|c|c|c|}
\hline Sample & $S_{\text {BET }}\left(\mathrm{m}^{2} / \mathrm{g}\right)$ & $V_{\mathrm{p}}\left(\mathrm{cm}^{3} / \mathrm{g}\right)$ & $d_{\text {ave }}{ }^{\mathrm{a}}(\mathrm{nm})$ & $\mathrm{Si} / \mathrm{Al}$ & wt\%Fe & wt $\% \mathrm{Cu}$ & $\mathrm{Si} / \mathrm{Fe}$ & $\mathrm{Si} / \mathrm{Cu}$ \\
\hline CuFeZSM-5 & 390.0 & 0.254 & 2.60 & No aluminum & 1.7 & 0.2 & 52.02 & 600.52 \\
\hline FeZSM-5 & 344.4 & 0.192 & 2.23 & No aluminum & 2.5 & - & 35.88 & No copper \\
\hline
\end{tabular}

\footnotetext{
a By BET method.
} 
(a)

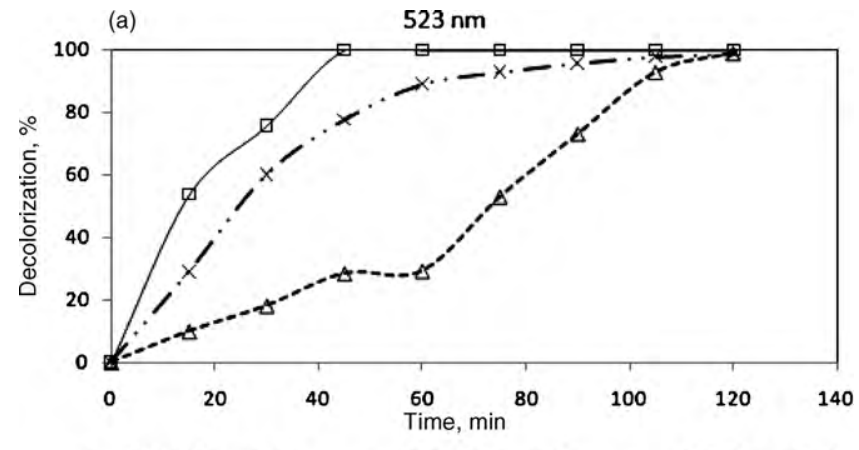

¿-CuFeZSM-5 at pH=3.4 --b-- CuFeZSM-5 at pH=6.5 — $\times$. FeZSM-5 at pH=3.4

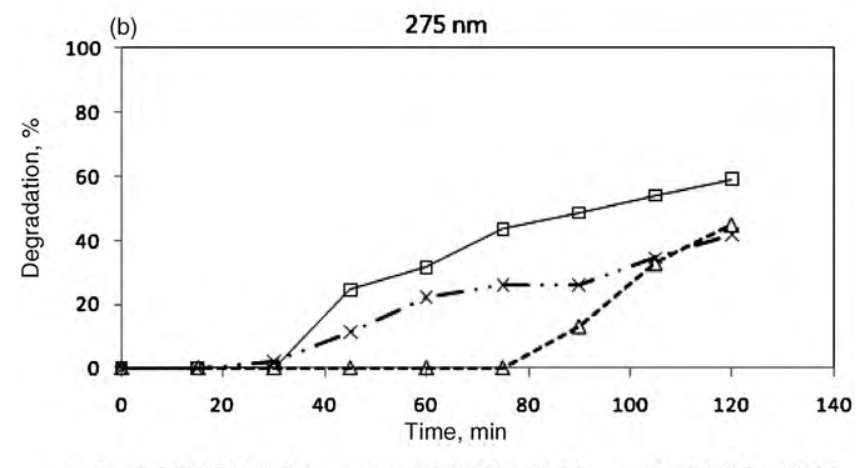

$\rightarrow$ CuFeZSM-5 at $\mathrm{pH}=3.4 \quad--t--$ CuFeZSM-5 at pH=6.5 $\rightarrow$. FeZSM-5 at pH=3.4

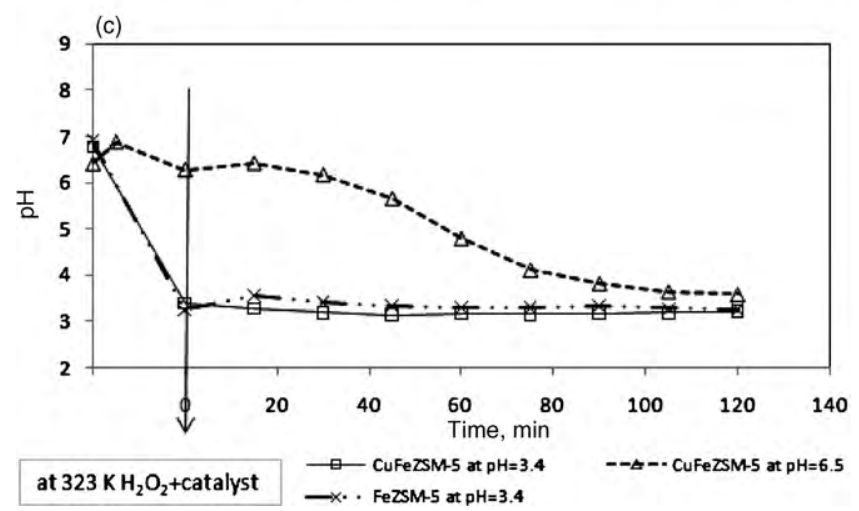

Fig. 2. The influence of catalyst type and pH on the oxidation of R6G (a) decolorization, (b) degradation \%, (c) $\mathrm{pH}$ value (Initial concentration of $\mathrm{R} 6 \mathrm{G}=0.1 \mathrm{~g} / \mathrm{dm}^{3}$, temperature $=323 \mathrm{~K}$, catalyst amount $=0.15 \mathrm{~g}$, solution volume $=0.15 \mathrm{dm}^{3}, \mathrm{H}_{2} \mathrm{O}_{2}$ amount $=40 \mathrm{mmol}$ ).

\section{Results and discussion}

\subsection{The influence of $\mathrm{pH}$ on catalytic oxidation}

Catalytic activity tests were performed under the conditions indicated in Section 2.3 for initial $\mathrm{pH}$ of 3.4. No noticeable dye removal by adsorption (blank run in the same conditions but without $\mathrm{H}_{2} \mathrm{O}_{2}$ ) took place during experiments over the prepared catalysts. Fig. 2 presents the results. A color removal of $100 \%$ was achieved after a reaction time of $45 \mathrm{~min}$ and degradation of naphthalene-like structures (hereafter it is called as degradation) was obtained to be $59.1 \%$ after $2 \mathrm{~h}$ oxidation when CuFeZSM-5 was used as catalyst, Fig. 2a and b. Addition of $\mathrm{H}_{2} \mathrm{O}_{2}$ to solution at the beginning of the reaction caused an increase in $\mathrm{pH}$ of the solution because of the oxidation of some $\mathrm{Fe}^{2+}$ species present in the zeolite. As the reaction proceeded, solution $\mathrm{pH}$ decreased to about 3.6. This phenomenon can be explained by the fragmentation of the azo dye molecules into organic acids which lead to a drop of $\mathrm{pH}$. For the same reaction duration, lower color and naphthalene ring removals were achieved with FeZSM-5 catalyst, $98.7 \%$ and $41.7 \%$, respectively. The difference in catalytic activity between CuFeZSM5 and FeZSM- 5 catalysts can be attributed to the introduction of copper into zeolite structure for CuFeZSM-5 catalyst. This sample had a larger surface area $\left(390.0 \mathrm{~m}^{2} / \mathrm{g}\right)$ and average pore diameter $(2.60 \mathrm{~nm})$ than those of FeZSM-5. Higher activity obtained may also arise from the fine dispersion of iron and copper in structure of CuFeZSM-5 zeolite. TOC elimination on CuFeZSM-5 was measured to be $51.8 \%$ after an oxidation time of $2 \mathrm{~h}$. At initial $\mathrm{pH}$ of 3.4 , the $\mathrm{pH}$ value remained almost unchanged during the oxidation. When the catalytic oxidation runs were performed at initial $\mathrm{pH}$ of 6.5 which was the $\mathrm{pH}$ of dye solution, $99 \%$ color removal was obtained after $2 \mathrm{~h}$ of reaction with CuFeZSM-5 catalyst. The achieved decolorization degree after $45 \mathrm{~min}$ was only $28.5 \%$. Initial rate of color removal was much lower, than that with initial pH of 3.4. Degradation at $275 \mathrm{~nm}$ and TOC removal after $2 \mathrm{~h}$ oxidation were measured to be $45 \%$ and $34 \%$, respectively.

There was a great difference in color (Fig. 2a) and naphthalene ring removal (Fig. 2b) for different initial $\mathrm{pH}$ values $(\mathrm{pH} 6.5$ and $\mathrm{pH}$ 3.4) during the early stage of the reaction for CuFeZSM- 5 catalyst. But this difference diminished after a reaction time of $2 \mathrm{~h}$ for decolorization. Decolorization after $2 \mathrm{~h}$ was complete, independent of pH. However, degradation and TOC abatement were affected significantly from the initial $\mathrm{pH}$ of dye solution. Degradation showed a decrease from $59.1 \%$ to $45 \%$ and TOC reduction decreased from $51.8 \%$ to $34 \%$ with the increase of $\mathrm{pH}$ from 3.4 to 6.5 , respectively. This is likely due to the formation of intermediates at nearly neutral $\mathrm{pH}$ whose mineralization is hindered [3].

Initial decolorization rate decreased with the increase in initial $\mathrm{pH}$ value, likely due to the accelerated formation of less reactive peroxy radicals, $\mathrm{H}_{2} \mathrm{O}^{\bullet}$, rather than $\mathrm{OH}^{\bullet}$ radicals [2].

On the other hand, an induction period was seen for degradation of dye over CuFeZSM-5 and FeZSM-5 catalysts, beyond which there was degradation of Rhodamine 6G. Induction period was about $30 \mathrm{~min}$ at $\mathrm{pH} 3.4$ and about $75 \mathrm{~min}$ at $\mathrm{pH}$ 6.5. This indicates that a certain minimum number of free radicals are required for the onset of the degradation process. Induction period was also reported by Gogate et al. [25] in sonolytic degradation of Rhodamine B.

During the CWPO runs of CuFeZSM-5 catalyst, amount of iron and copper loss into the solution was determined by measuring the iron and copper concentration in the solution after a reaction time of $2 \mathrm{~h}$ with atomic absorption spectrophotometer (Varian 10 plus). Iron leached was measured to be $0.7 \mathrm{mg} / \mathrm{dm}^{3}$ (loss \% = 4) at initial $\mathrm{pH}$ of 6.5 and $0.8 \mathrm{mg} / \mathrm{dm}^{3}$ (loss \% = 4.6) at pH 3.4. Copper loss was more significant, $1.4 \mathrm{mg} / \mathrm{dm}^{3}$ (loss \%=82.4) at $\mathrm{pH} 6.5$ and $2.1 \mathrm{mg} / \mathrm{dm}^{3}$ (loss $\%=100$ ) at $\mathrm{pH} 3.4$. It means that at $\mathrm{pH} 3.4$ the copper was totally leached from the catalyst during the process. Consequently, the leaching of iron and copper cations from zeolite structure into the solution was strongly dependent on $\mathrm{pH}$ [17]. Even though iron leaching increased with the regulation of $\mathrm{pH}$ to about 3.4, leached amount of iron was below the EU directives $\left(<2 \mathrm{mg} / \mathrm{dm}^{3}\right)$.

In order to determine the homogeneous contribution of leached ions to total activity, a couple of runs were performed with homogeneous catalysts at the concentration of dissolved ions and no color removal and degradation of dye were obtained. This result supported the idea that introduction of copper into the FeZSM-5 zeolite had a synergetic effect rather than catalytic in degradation of dye.

The highest color removal, degradation and TOC elimination were obtained with CuFeZSM-5 catalyst at initial $\mathrm{pH}$ of 3.4. The effects of amount of $\mathrm{H}_{2} \mathrm{O}_{2}$, concentration of the catalyst and temperature were investigated on R6G oxidation and kinetics of the oxidation reaction was studied over this catalyst. 


\subsection{The influence of $\mathrm{H}_{2} \mathrm{O}_{2}$ amount on oxidation}

Before investigating the influence of $\mathrm{H}_{2} \mathrm{O}_{2}$ amount on oxidation of Rhodamine 6G (R6G), blank experiments were carried out. In the absence of the catalyst, when $\mathrm{H}_{2} \mathrm{O}_{2}$ was present alone, a color removal of $91 \%$ was recorded, but no degradation was achieved. In the presence of CuFeZSM-5 catalyst alone (without $\mathrm{H}_{2} \mathrm{O}_{2}$ ) neither color removal nor degradation was obtained at initial $\mathrm{pH}$ of 3.4 after a reaction time of $2 \mathrm{~h}$. These results show that CuFeZSM- 5 catalyst is effective when it is present in the dye solution with $\mathrm{H}_{2} \mathrm{O}_{2}$ together.

The catalytic oxidation runs for different $\mathrm{H}_{2} \mathrm{O}_{2}$ concentrations were carried out using the following operational conditions: Initial $\mathrm{pH}$ of 3.4 , catalyst amount of $0.15 \mathrm{~g} / 0.15 \mathrm{dm}^{3}$, initial concentration of R6G of $0.1 \mathrm{~g} / \mathrm{dm}^{3}$, temperature of $323 \mathrm{~K}$. The results are presented in Fig. 3. The increase in $\mathrm{H}_{2} \mathrm{O}_{2}$ concentration from 10 to $80 \mathrm{mmol}$ accelerated the initial decolorization rate of Rhodamine $6 \mathrm{G}$ from $4.72 \times 10^{-6}$ to $9.26 \times 10^{-6} \mathrm{~mol} / \mathrm{dm}^{3} \mathrm{~min}$. This phenomenon can be explained by the effect of $\mathrm{OH}^{\bullet}$ radicals produced additionally. However, color removal after $2 \mathrm{~h}$ of reaction duration was not altered significantly with the increase in the mole ratio of $\mathrm{H}_{2} \mathrm{O}_{2}$ and dye from 9:1 to 75:1 for a reaction time of $120 \mathrm{~min}$. At $\mathrm{H}_{2} \mathrm{O}_{2}$ initial concentration of $10 \mathrm{mmol} / 0.15 \mathrm{dm}^{3} 97.7 \%$ and at $20 \mathrm{mmol} / 0.15 \mathrm{dm}^{3}$ $100 \%$ decolorization were obtained after $2 \mathrm{~h}$ of reaction. However, at doses of 40 and $80 \mathrm{mmol} \mathrm{H}_{2} \mathrm{O}_{2}$, almost complete color removal was achieved after $45 \mathrm{~min}$ of reaction time. Similar result has been reported by Chaliha and Bhattocharyya [16] in the wet oxidative removal of 2,4,6-tricholorophenol in water using Fe (III), Co (II), Ni (II) supported MCM41 catalysts. This could be explained by different by-products coming from the partial oxidation of the dye.

For the intermediate $\mathrm{H}_{2} \mathrm{O}_{2}$ concentrations (20 and $40 \mathrm{mmol}$ ), a similar behavior in term of degradation was observed $(60.4 \%$ and $59.1 \%)$. Whereas the reaction took place more slowly when the concentration was the lowest $(10 \mathrm{mmol})$ or the highest $(80 \mathrm{mmol})$. The increase of the oxidant concentration from $10 \mathrm{mmol}$ to $40 \mathrm{mmol}$ led to an increase in degradation from $52.9 \%$ to $59.1 \%$, because more radicals would be formed. Nevertheless, for the highest $\mathrm{H}_{2} \mathrm{O}_{2}$ concentration $(80 \mathrm{mmol})$ degradation of naphthalene ring decreases to $48 \%$. This was because of the scavenging of $\mathrm{HO}^{\bullet}$ radicals which occurs by the following reaction:

$\mathrm{H}_{2} \mathrm{O}_{2}+\mathrm{HO}^{\bullet} \rightarrow \mathrm{H}_{2} \mathrm{O}+\mathrm{HO}_{2}^{\bullet}$

Produced hydroperoxyl radicals $\left(\mathrm{HO}_{2}{ }^{\bullet}\right)$ are less reactive than $\mathrm{OH}^{\bullet}$ species. The existence of an optimum $\mathrm{H}_{2} \mathrm{O}_{2}$ concentration is well known in Fenton's oxidation. The selection of the optimum value is important from the commercial point of view (due to the cost of $\mathrm{H}_{2} \mathrm{O}_{2}$ ). This optimum value, for the conditions used in this study, seems to be $40 \mathrm{mmol}$ rather than $20 \mathrm{mmol}$ because initial decolorization rate at $40 \mathrm{mmol}$ of $\mathrm{H}_{2} \mathrm{O}_{2}$ is much higher than that at $20 \mathrm{mmol}$ of $\mathrm{H}_{2} \mathrm{O}_{2}$ (Fig. 3a). Solution pH was not affected significantly by $\mathrm{H}_{2} \mathrm{O}_{2}$ concentration used in the run, Fig. 3c. TOC removal at different $\mathrm{H}_{2} \mathrm{O}_{2}$ concentrations are presented in Fig. 3d at an initial pH of 3.4. The increase of $\mathrm{H}_{2} \mathrm{O}_{2}$ amount from 20 to $80 \mathrm{mmol}$ causes a drastic enhancement in TOC removal from $1.7 \%$ to $69.6 \%$. The increase of TOC elimination and the decrease of naphthalene ring removal with hydrogen peroxide concentration indicate that benzene ring removal is enhanced by the increase of $\mathrm{H}_{2} \mathrm{O}_{2}$ concentration. The effect of $\mathrm{H}_{2} \mathrm{O}_{2}$ on degradation and TOC removal being similar to those reported by Ramirez et al. [4] in the Fenton-like oxidation of Orange II solutions over heterogeneous catalysts based on saponite clay, by Dutta et al. [26] in the chemical oxidation of methylene blue using a Fenton-like reaction, by Guedes et al. [27] in the Fenton oxidation of cork cooking waste water and by Stolyarova et al. [3] in oxidative degradation of Rhodamine 6G over FeZSM-5 zeolites.

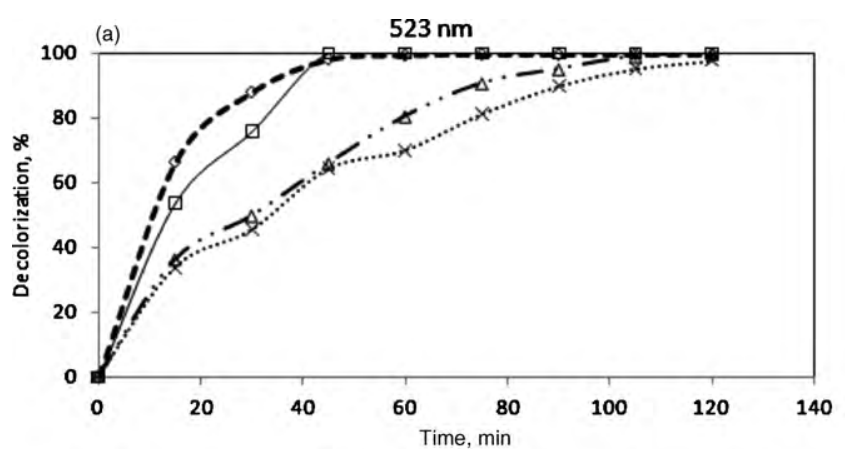

......... $10 \mathrm{mmol} \mathrm{H} 2 \mathrm{O} 2 \longrightarrow . .20 \mathrm{mmol} \mathrm{H} 2 \mathrm{O} 2 \rightarrow-40 \mathrm{mmOl} \mathrm{H} 2 \mathrm{O} 2 \longrightarrow-80 \mathrm{mmol} \mathrm{H} 2 \mathrm{O} 2$
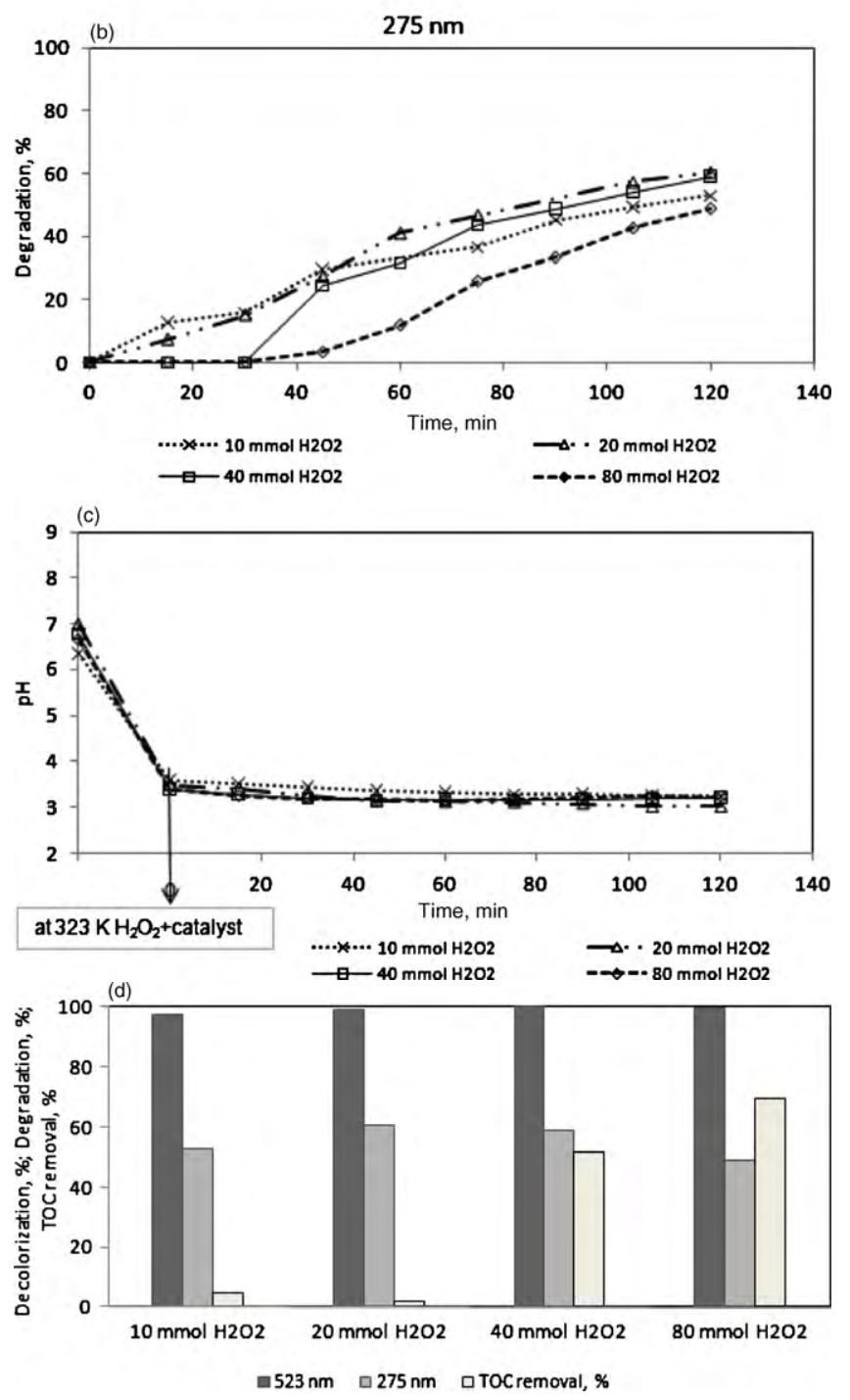

Fig. 3. Catalytic oxidation runs for different $\mathrm{H}_{2} \mathrm{O}_{2}$ concentrations on CuFeZSM-5 catalyst (a) decolorization, (b) degradation \%, (c) pH value, (d) TOC \% removal (Initial concentration of $\mathrm{R} 6 \mathrm{G}=0.1 \mathrm{~g} / \mathrm{dm}^{3}$, temperature $=323 \mathrm{~K}$, catalyst amount $=0.15 \mathrm{~g}$, solution volume $=0.15 \mathrm{dm}^{3}, \mathrm{pH} 3.4$ ).

\subsection{The influence of catalyst concentration}

The influence of catalyst concentration on azo dye R6G removal using CuFeZSM-5 catalyst was studied by using $0.15 \mathrm{~g}(1 \mathrm{~g}$ cat./ $\mathrm{dm}^{3}$-soln.) and $0.3 \mathrm{~g}$ catalyst ( $2 \mathrm{~g}$-cat. $/ \mathrm{dm}^{3}$-soln.) for $0.15 \mathrm{dm}^{3}$ dye solution under the following reaction conditions: Initial R6G concentration of $0.1 \mathrm{~g} / \mathrm{dm}^{3}$, temperature of $323 \mathrm{~K}$, initial $\mathrm{pH}$ of 

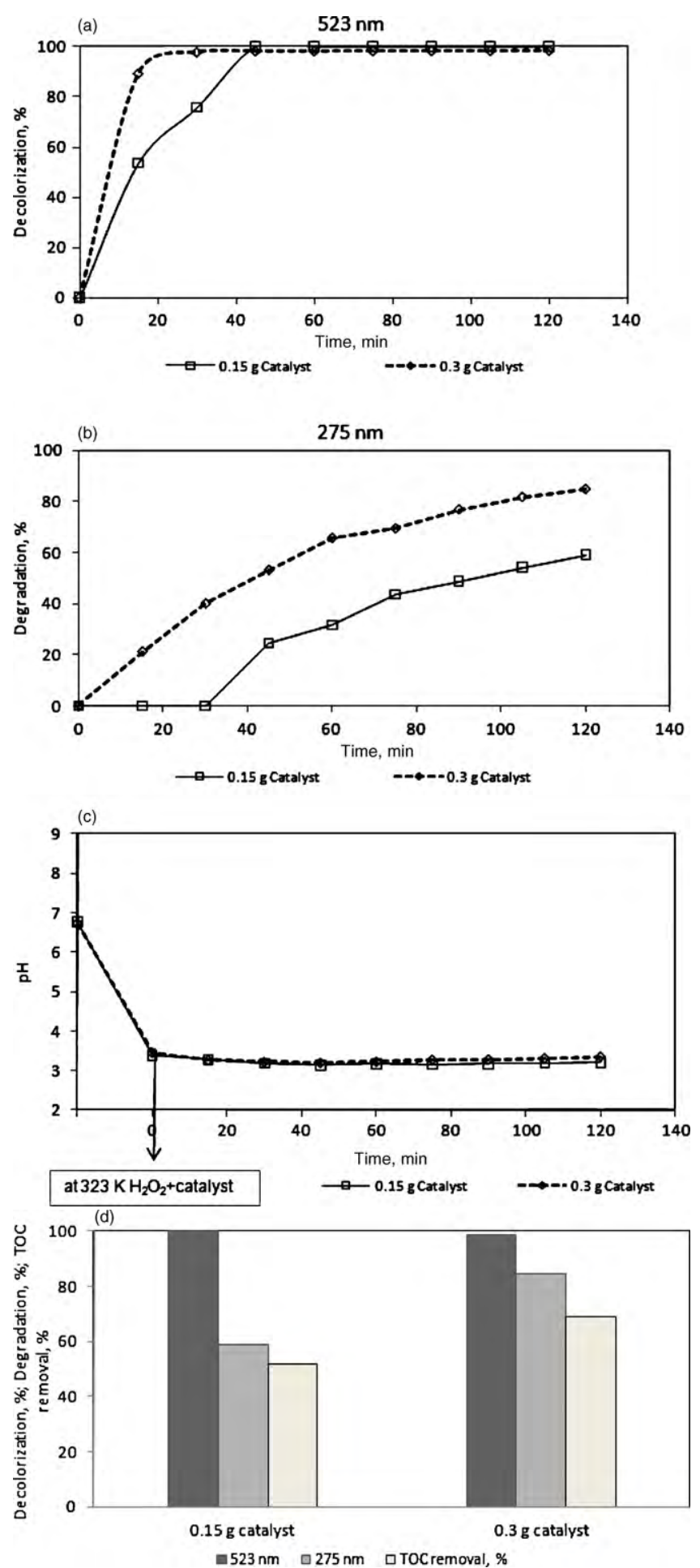

Fig. 4. Catalytic oxidation runs for different catalyst concentrations on CuFeZSM-5 catalyst (a) decolorization, (b) degradation \%, (c) pH value, (d) TOC \% removal (Initial concentration of $\mathrm{R} 6 \mathrm{G}=0.1 \mathrm{~g} / \mathrm{dm}^{3}$, temperature $=323 \mathrm{~K}, \mathrm{H}_{2} \mathrm{O}_{2}$ amount $=40 \mathrm{mmol}$, solution volume $=0.15 \mathrm{dm}^{3}, \mathrm{pH} 3.4$ ).

3.4. Results are presented in Fig. 4. A significant increase in initial color removal rate was observed when catalyst concentration was increased from 1 to $2 \mathrm{~g} / \mathrm{dm}^{3}$. A complete color removal was achieved after $45 \mathrm{~min}$ of reaction time for both of the catalyst concentrations. Nevertheless, degradation was more efficient than color removal throughout the catalytic process with $2 \mathrm{~g} / \mathrm{dm}^{3}$ catalyst concentration; $84.6 \%$ removal with $2 \mathrm{~g} / \mathrm{dm}^{3}$ catalyst, but $59.1 \%$
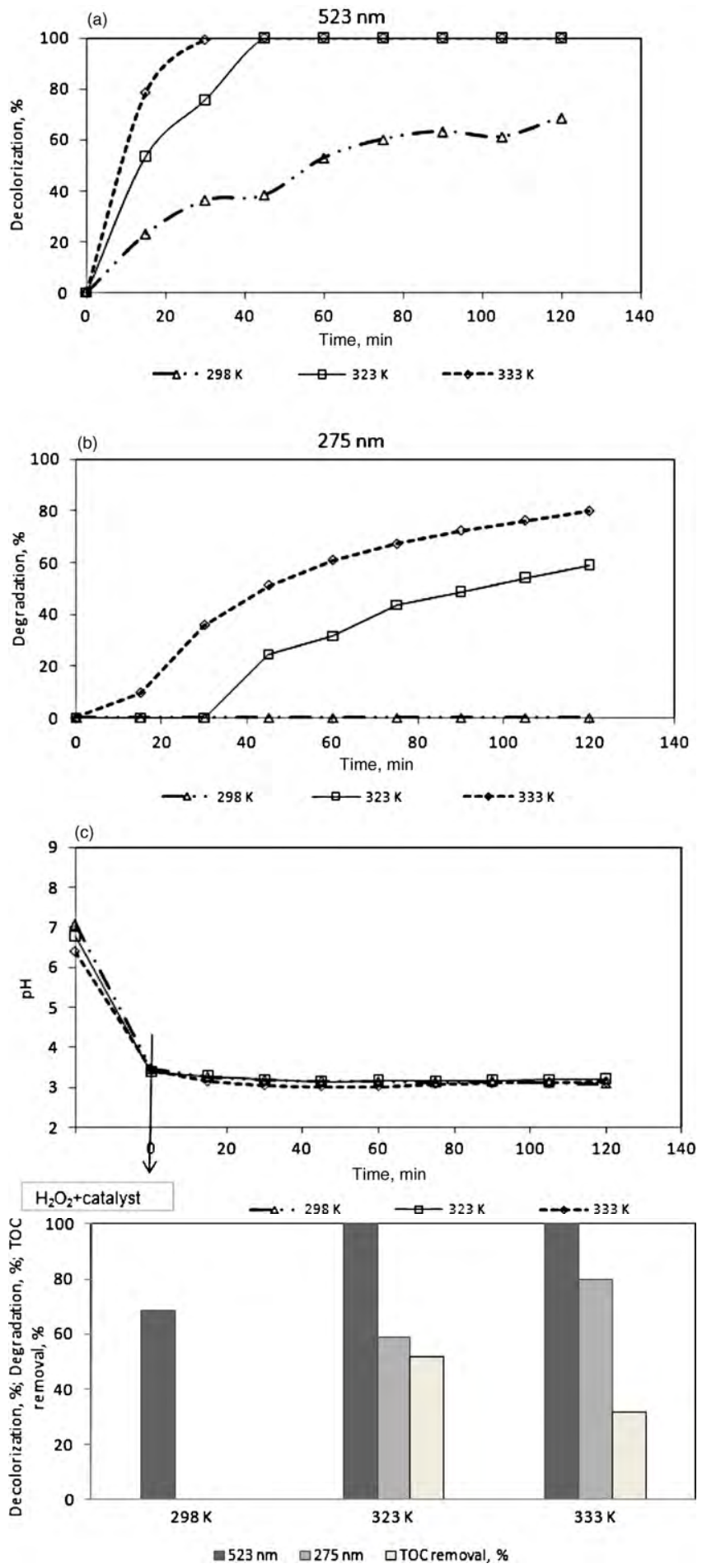

Fig. 5. Catalytic oxidation runs for different temperatures on CuFeZSM-5 catalyst (a) decolorization, (b) degradation \%, (c) pH value, (d) TOC \% removal (Initial concentration of $\mathrm{R} 6 \mathrm{G}=0.1 \mathrm{~g} / \mathrm{dm}^{3}$, catalyst amount $=0.15 \mathrm{~g}, \mathrm{H}_{2} \mathrm{O}_{2}$ amount $=40 \mathrm{mmol}$, solution volume $=0.15 \mathrm{dm}^{3}, \mathrm{pH} 3.4$ ).

with $1 \mathrm{~g} / \mathrm{dm}^{3}$ of catalyst. Solution $\mathrm{pH}$ was not affected by catalyst concentration, Fig. 4c. Iron and copper loss by leaching from the catalyst in the $2 \mathrm{~g}$ of catalyst $/ \mathrm{dm}^{3}$ experiment were measured to be $3.45 \%$ and $100 \%$, respectively. This result was very similar to that obtained by $1 \mathrm{~g}$ of catalyst $/ \mathrm{dm}^{3}$ experiment.

TOC removal increased with increasing amount of catalyst, Fig. 4d. When the catalyst amount was doubled, TOC elimination changed from $51.8 \%$ to $68.8 \%$. Similar trend for the influence of cat- 


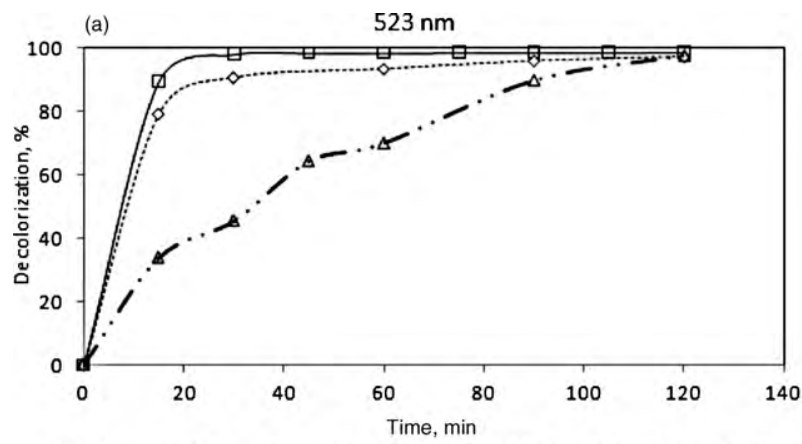

$\square$ Fresh catalyst $\cdots-$ Used catalyst $\rightarrow$. . Used catalyst washed with ethanol

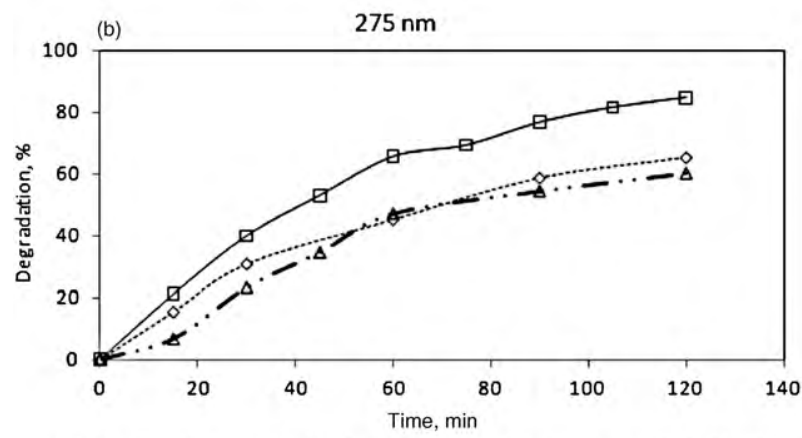

$\square$ Freshcatalyst $\cdots-.-$ Used catalyst $\rightarrow$ U Used catalyst washed with ethanol
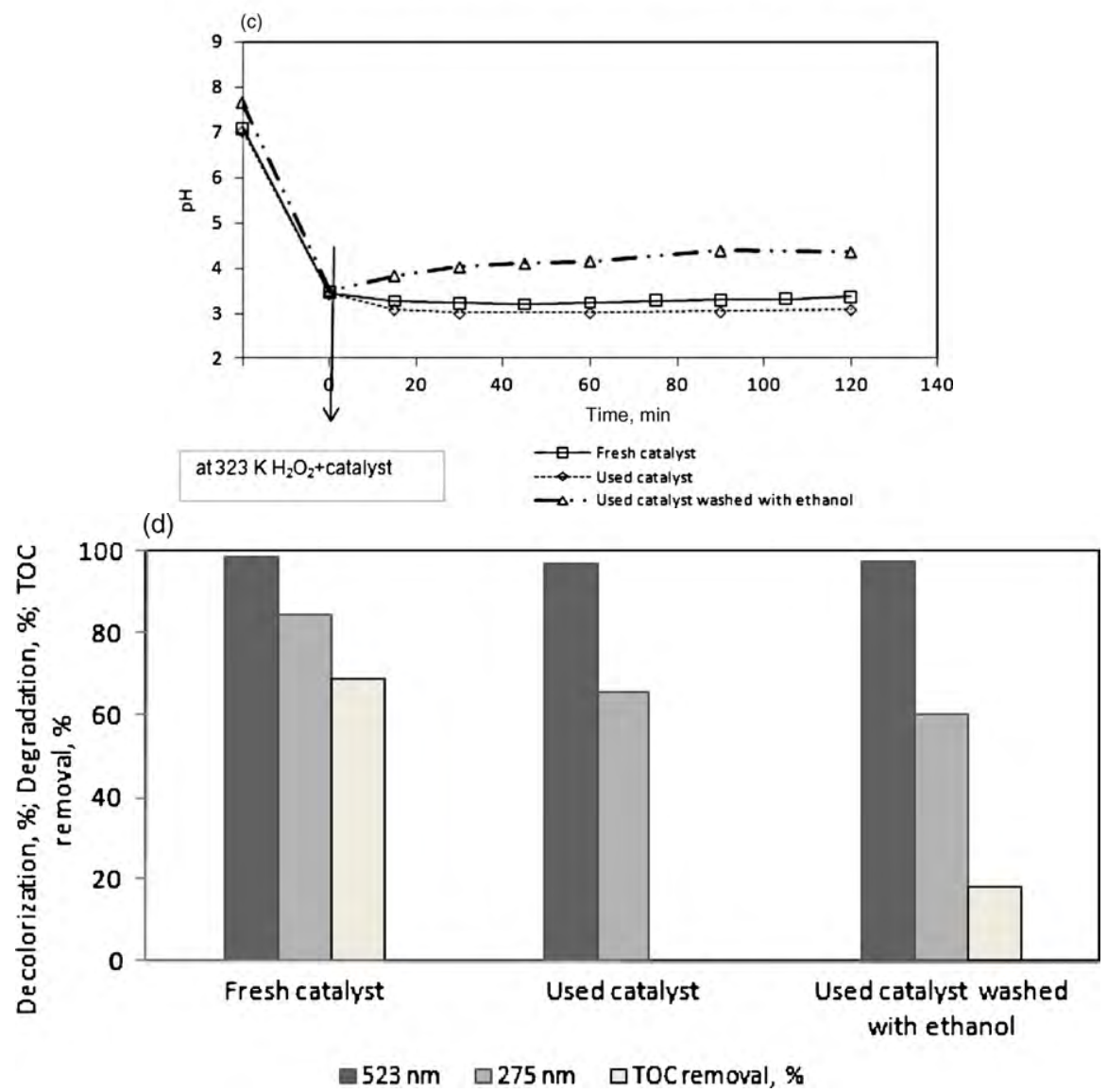

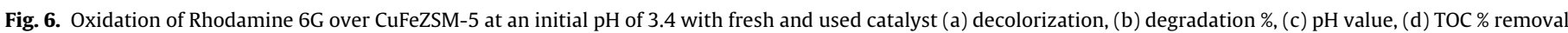
(Initial concentration of $\mathrm{R} 6 \mathrm{G}=0.1 \mathrm{~g} / \mathrm{dm}^{3}$, catalyst amount $=0.3 \mathrm{~g}$, temperature $=323 \mathrm{~K} \mathrm{H}_{2} \mathrm{O}_{2}$ amount $=40 \mathrm{mmol}$, solution volume $=0.15 \mathrm{dm}{ }^{3}$, $\mathrm{pH} 3.4$ ). 
alyst concentration on dye oxidation was reported by Neamtu et al. [2] for CWPO of reactive azo dye Procion Marine H-EXL over Fe-exchanged Y zeolite.

\subsection{Temperature effect}

The degradation kinetics of aqueous dye solution was investigated for different temperatures, 298, 323 and $333 \mathrm{~K}$ under the following conditions over CuFeZSM-5 catalyst: initial R6G concentration of $0.1 \mathrm{~g}$-dye $/ \mathrm{dm}^{3}$, catalyst amount of $0.15 \mathrm{~g} / 0.15 \mathrm{dm}^{3}$ dye solution, initial $\mathrm{pH}$ of 3.4 . The results presented in Fig. 5 showed clearly that the color removal rate and degradation rate increased with increasing temperature, which was expected due to the exponential dependency of the rate constant with the reaction temperature. The lowest decolorization degree was measured at a temperature of $298 \mathrm{~K}$. Nevertheless, complete color removal was obtained after $45 \mathrm{~min}$ of reaction time at 323 and $333 \mathrm{~K}$.

As expected, degradation increased with the temperature being $59.1 \%$ at $323 \mathrm{~K}$ and $79.8 \%$ at $333 \mathrm{~K}$. No degradation was observed at $298 \mathrm{~K}$.

Fig. 5d presents the effect of temperature on TOC abatement. No TOC removal was obtained at $298 \mathrm{~K}$ and TOC elimination was enhanced with the increase in temperature from 298 to $323 \mathrm{~K}$ where it was $51.8 \%$. Nevertheless, the TOC elimination obtained at $333 \mathrm{~K}$ was lower (31.8\%) than that at $323 \mathrm{~K}(51.8 \%)$. Similar result has been found during CWPO of Orange II over Fe-saponite catalysts [4]. The lower performance achieved than expected at high temperatures was attributed to the accelerated decomposition of $\mathrm{H}_{2} \mathrm{O}_{2}$ into oxygen and water which causes a decrease in degradation degree of dye. On the other hand, the low TOC removal at higher temperature $(333 \mathrm{~K})$ may be explained by the production of small organic molecular fragments which are not completely mineralized under the oxidation conditions used [2].

\subsection{Stability and recycling of the catalyst}

For a practical implementation of a heterogeneous catalytic system, it is crucial to evaluate the stability of the catalysts. To recover the catalyst, the final effluent was filtrated and dried or washed with ethanol. These catalysts were called as used catalyst and used catalyst washed with ethanol, respectively. The latter one was calcined by heating to $423 \mathrm{~K}$ and keeping there for $15 \mathrm{~min}$ then heating to $873 \mathrm{~K}$ and keeping at this temperature for $2 \mathrm{~h}$ to remove the adsorbed organic species from the active sites [4,28]. The activities of these catalysts in R6G decolorization and degradation were presented in Fig. 6. Eventhough initial decolorization rate became lower than with fresh catalyst, no significant decay in decolorization degree of the dye solution was observed after a reaction time of $2 \mathrm{~h}$ when used catalyst or used catalyst washed with ethanol were tested. However, an appreciable activity decay, from $84.6 \%$ with fresh catalyst to $65.5 \%$ with used catalyst and to $60.2 \%$ with used catalyst washed with ethanol was measured in naphthalene ring removal of Rhodamine $6 \mathrm{G}$ dissolved in water. A pronounced decay in initial degradation rate was obtained on used catalyst washed with ethanol. The results showed that the loss of activity could not be attributed to poisoning of the catalytic sites due to the adsorbed organic species as thermal treatment was applied. The lower activity of the used and washed catalyst could be due to copper leaching from the catalyst. There was no copper in the used catalyst. Thus, synergetic effect of copper was not included in the reactions with used catalyst and used catalyst washed with ethanol.

Solution pH was not affected (around 3.1-3.4) by the presence of fresh and used catalyst in the system. However, when catalyst washed with ethanol was used in oxidation, reaction was preceded at a higher $\mathrm{pH}$ of 4.4 .

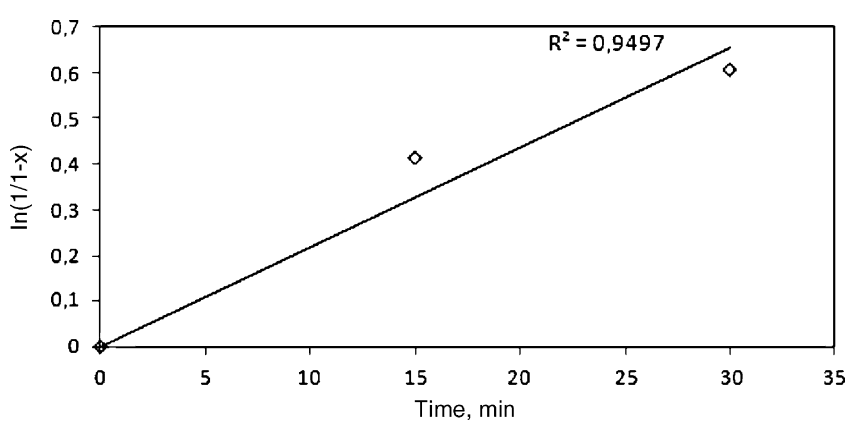

Fig. 7. $\ln (1 / 1-x)$ vs. time plot at $323 \mathrm{~K}$ in the presence of $10 \mathrm{mmol} \mathrm{H}_{2} \mathrm{O}_{2}$.

TOC elimination measured with used catalyst is shown in Fig. 6d. There was no TOC removal with used catalyst. However, after the used catalyst was washed with ethanol and then calcined, a TOC removal of $18.3 \%$ was measured which was much lower than that with fresh catalyst (68.8\%).

\subsubsection{Decolorization kinetics of catalytic oxidation of Rhodamine} $6 G$

The decolorization kinetics was determined for initial rate, $-r_{\mathrm{A} 0}$, over CuFeZSM-5 catalyst at initial pH of 3.4. Data at reaction times of 0,15 and $30 \mathrm{~min}$ were used for initial rate calculations. For determining the reaction order, several orders were tested and first order rate equation best fit the initial data. For this purpose, a plot of $\ln (1 / 1-x)$ vs. time (where $x$ is decolorization degree) was drawn by using decolorization data in the range of 0-30 min for a known amount of $\mathrm{H}_{2} \mathrm{O}_{2}$ added to the solution initially. Fig. 7 presents that plot for R6G initial concentration of $0.1 \mathrm{~g} / \mathrm{dm}^{3}$ $\left(2.087 \times 10^{-4} \mathrm{~mol} / \mathrm{dm}^{3}\right)$ at $323 \mathrm{~K}$ in the presence of $10 \mathrm{mmol} \mathrm{H}_{2} \mathrm{O}_{2}$.

First order dependency of decolorization rate was in a good accordance with those reported in literature for dyes $[2,29,30]$.

The order with respect to $\mathrm{H}_{2} \mathrm{O}_{2}$ concentration was determined by plotting $\ln \left(-r_{\mathrm{A} 0}\right)$ against $\ln \left(\mathrm{C}_{\mathrm{H}_{2} \mathrm{O}_{2}, 0}\right)$. The slope of the straight line obtained was equal to the order with respect to concentration of $\mathrm{H}_{2} \mathrm{O}_{2}$. Fig. 8 presents the variation of initial rate with respect to initial concentration of $\mathrm{H}_{2} \mathrm{O}_{2}$ for $\mathrm{R} 6 \mathrm{G}$ initial concentration of $0.1 \mathrm{~g} / \mathrm{dm}^{3}$ over CuFeZSM-5 catalyst at initial pH of 3.4 and $323 \mathrm{~K}$. As seen from Fig. 8, order was equal to $0.3481-0.35$ in the range of $10-80 \mathrm{mmol}$ initial concentration of $\mathrm{H}_{2} \mathrm{O}_{2}$.

Fig. 9 presents the Arrhenius plot of $\ln k$ vs. $1 / T$ obtained by using the decolorization data for $40 \mathrm{mmol}\left(0.267 \mathrm{~mol} / \mathrm{dm}^{3}\right) \mathrm{H}_{2} \mathrm{O}_{2}$ and $2.087 \times 10^{-4} \mathrm{~mol} / \mathrm{dm}^{3} \mathrm{R} 6 \mathrm{G}$ at different temperatures, namely 298,323 and $333 \mathrm{~K}$.

From the slope of Arrhenius plot in Fig. 9, $-E / R$, where $R$ is universal gas constant $\left(8.314 \times 10^{-3} \mathrm{~kJ} / \mathrm{mol} \mathrm{K}\right)$, activation energy $(E)$ was calculated to be $24.83 \mathrm{~kJ} / \mathrm{mol}$. Consequently, initial decoloriza-

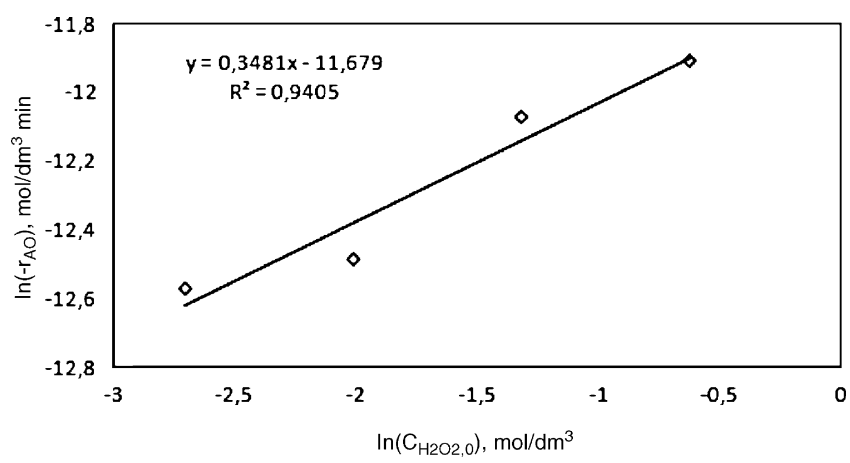

Fig. 8. Variation of initial rate with respect to initial concentration of $\mathrm{H}_{2} \mathrm{O}_{2}$. 


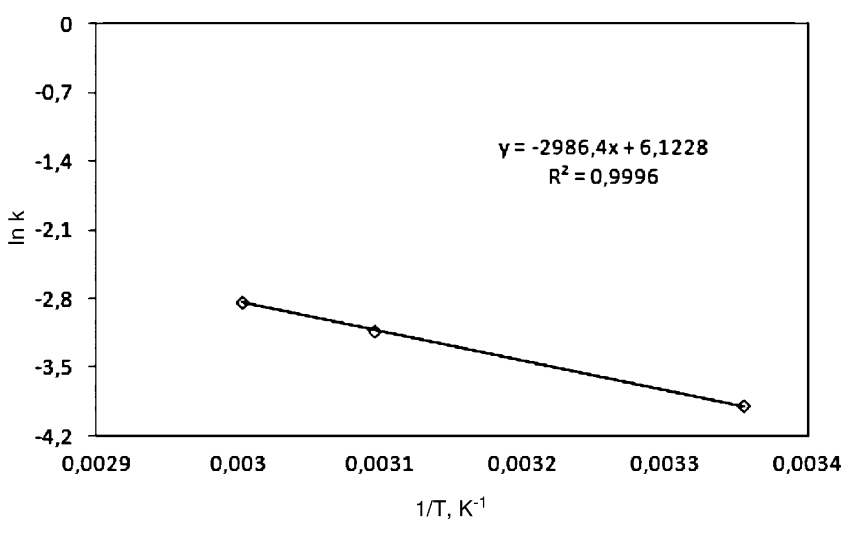

Fig. 9. Arrhenius plot of $\ln k$ vs. $1 / T$.

tion rate can be expressed by the following equation;

$-r_{\mathrm{A} 0}=4.56 \times 10^{2} e^{-24.83 / R T} C_{\mathrm{R} 6 \mathrm{G}, 0} C_{\mathrm{H}_{2} \mathrm{O}_{2}, 0}^{0.35}$

Activation energy of $35.9 \mathrm{~kJ} / \mathrm{mol}$ was reported for the rapid decolorization of azo dye methyl orange in aqueous solution by nanoscale zerovalent iron particles [31]. Moreover, activation energy of homogeneous catalytic Fenton oxidation of Reactive Brillant Blue X-BR azo dye was given in literature to be $25.21 \mathrm{~kJ} / \mathrm{mol}$ [32]. The activation energy obtained in this study for oxidation of R6G was very close to that given for the latter azo dye oxidation.

\section{Conclusions}

Higher activities were obtained over CuFeZSM5 catalyst compared to FeZSM-5. This was due to the presence of $\mathrm{Cu}$. Higher color removal and degradation were observed at initial solution $\mathrm{pH}$ of 3.4 compared to $\mathrm{pH}$ of 6.5 . A color removal of $100 \%$ was obtained after a reaction time of 45 min over CuFeZSM- 5 catalyst at low pH. Degradation and TOC elimination were measured to be $59.1 \%$ and $51.8 \%$ after an oxidation time of $2 \mathrm{~h}$. The decrease of color removal and degradation at high $\mathrm{pH}$ was attributed to the accelerated formation of less reactive hydroperoxyl radicals, $\mathrm{HO}_{2}{ }^{\bullet}$, rather than $\mathrm{OH}^{\bullet}$ radicals. The increase in $\mathrm{H}_{2} \mathrm{O}_{2}$ concentration from 10 to $80 \mathrm{mmol}$ increased initial decolorization rate of Rhodamine 6G. Initial color removal rate increased significantly with the catalyst amount. TOC elimination changed depending on the temperature of the solution. It first increased and then decreased. This phenomenon was explained by the accelerated decomposition of $\mathrm{H}_{2} \mathrm{O}_{2}$ into oxygen and formation of small organic molecules which were not completely mineralized under the reaction conditions studied. Reaction activation energy was calculated as $24.83 \mathrm{~kJ} / \mathrm{mol}$.

\section{Acknowledgements}

The authors acknowledge the financial support from TUBITAK (The Scientific and Technological Research Council of Turkey) and NASU (National Academy of Sciences of Ukraine) under project number of 107M625. The authors also thank for financial support from Ege University under the project number of 2009BiL030 and Ceyda Yaman for her help in catalyst preparation and characterization studies.

\section{References}

[1] G. Tezcanl1-Guyer, N.H. Ince, Degradation and toxicity reduction of textile dyestuff by ultrasound, Ultrason. Sonochem. 10 (2003) 235-240.

[2] M. Neamtu, C. Zaharia, C. Catrinescu, A. Yediler, M. Macoveanu, A. Kettrup, Feexchanged $\mathrm{Y}$ zeolite as catalyst for wet peroxide oxidation of reactive azo dye Procion Marine H-EXL, Appl. Catal. B-Environ. 48 (2004) 287-294.
[3] I.V. Stolyarova, I.B. Kovban, R.V. Prikhod'ko, A.O. Kushko, M.V. Sychev, V.V. Goncharuk, FeZSM-5 zeolites in oxidative degradation of dyes and the nature of their active centers, Russ. J. App. Chem. 80/5 (2007) 746-753.

[4] J.H. Ramirez, C.A. Costa, L.M. Madeira, G. Mata, M.A. Vicente, M.L. RojasCervantes, A.J. Lopez-Peinado, R.M. Martin-Aranda, Fenton-like oxidation of Orange II solutions using heterogeneous catalysts based on saponite clay, Appl. Catal. B-Environ. 71 (2007) 44-56.

[5] C. Wailling, Fenton's reagent revisited, Acc. Chem. Res. (1975) 125-131.

[6] M. Neamtu, A. Yediler, I. Siminiceanu, A. Kettrup, Oxidation of commercial reactive azo dye aqueous solutions by the photo-Fenton and Fenton-like processes, J. Photochem. Photobiol. A: Chem. 161 (2003) 87-93.

[7] G. Bertanza, C. Collivignarelli, R. Pedrazzani, The role of chemical oxidation in combined chemical-physical and biological processes: experiences of industrial wastewater treatment, Water Sci. Technol. 44 (2001) 109-116.

[8] E.G. Solozhenko, N.M. Soboleva, V.V. Goncharuk, Decolourization of azodye solutions by Fenton's oxidation, Water Res. 29 (1995) 2206-2210.

[9] S.F. Kang, H.M. Chang, Coagulation of textile secondary effluents with Fenton's reagent, Water Sci. Technol. 36 (1997) 215-222.

[10] A.H. Gemeay, I.A. Mansour, R.G. El-Sharkawy, A.B.Zaki, Kinetics and mechanism of the heterogeneous catalyzed oxidative degradation of indigo carmine, J. Mol. Catal. A-Chem. 193 (2003) 109-120.

[11] V.V. Ishtchenko, K.D. Huddersman, R.F. Vitkovskaya, Part 1. Production of a modified PAN fibrous catalyst and its optimisation towards the decomposition of hydrogen peroxide, Appl. Catal. A-Gen. 242 (2003) 123-137.

[12] S. Letaief, B. Casal, P. Aranda, M.A. Martín-Luengo, E. Ruiz-Hitzky, Fe-containing pillared clays as catalysts for phenol hydroxylation, Appl. Clay Sci. 22 (2003) 263-277.

[13] G. Tachiev, J.A. Roth, A.R. Bowers, Kinetics of hydrogen peroxide decomposition with complexed and "free" iron catalyst, Int. J. Chem. Kinet. 32 (2000) 24-35.

[14] F. Martínez, G. Calleja, J.A. Melero, R. Molina, Heterogeneous photo-Fenton degradation of phenolic aqueous solutions over iron-containing SBA-15 catalyst, Appl. Catal. B-Environ. 60 (2005) 181-190.

[15] N.H. Phu, T.T.K. Hoa, N. Van Tan, H.V. Thang, P. Le Ha, Characterization and activity of Fe-ZSM-5 catalysts for the total oxidation of phenol in aqueous solutions, Appl. Catal. B-Environ. 34 (2001) 267-275.

[16] S. Chaliha, K.G. Bhattocharyya, Wet oxidative method for removal of 2,4,6 trichlorophenol in water using $\mathrm{Fe}(\mathrm{III}), \mathrm{Co}(\mathrm{II}), \mathrm{Ni}(\mathrm{II})$ supported MCM41 catalysts, J. Hazard. Mater. 150 (2008) 728-736.

[17] R. Centi, S. Parathoner, T. Torre, M.G. Verduna, Catalytic wet oxidation with $\mathrm{H}_{2} \mathrm{O}_{2}$ of carboxylic acids on homogeneous and heterogeneous Fenton-type catalysts, Catal. Today 55 (2000) 61-69.

[18] K. Pirkanniami, M. Sillanpaa, Heterogeneous water phase catalysis as an environmental application: a review, Chemosphere 48 (2002) 1047-1060.

[19] A.V. Kucherov, A.N. Shigapov, A.V. Ivanov, T.N. Kucherova, L.M. Kustov, Distribution and properties of catalytically active $\mathrm{Cu}^{2+}$-sites on a mesoporous MCM-41 silicate modified by Al, Zr, W, B, or P ions, Catal. Today 110 (2005) 330 338.

[20] H. Sjövall, L. Olsson, E. Fridell, R.J. Blint, Selective catalytic reduction of $\mathrm{NO}_{x}$ with $\mathrm{NH}_{3}$ over $\mathrm{Cu}-\mathrm{ZSM}-5-$ the effect of changing the gas composition, Appl. Catal. B-Environ. 64 (2006) 180-188.

[21] L. Olsson, H. Sjövall, R.J. Blint, A kinetic model for ammonia selective catalytic reduction over Cu-ZSM-5, Appl. Catal. B-Environ. 81 (2008) 203-217.

[22] S.A. Yashnik, Z.R. Ismagilov, V.F. Anufrienko, Catalytic properties and electronic structure of copper ions in Cu-ZSM-5, Catal. Today 110 (2005) 310-322.

[23] R. Szostak, V. Nair, T.L. Thomas, Incorporation and stability of iron in molecularsieve structures: ferrisilicate analogues of zeolite ZSM-5, J. Chem. Soc. Faraday Trans. 183 (1987) 487-494.

[24] M. Dükkancı, G. Gündüz, S. Yılmaz, Y.C. Yaman, R.V. Prihod'ko, I.V. Stolyarova Characterization and catalytic activity of CuFeZSM-5 catalysts for oxidative degradation of Rhodamine 6G in aqueous solutions, Appl. Catal. B-Environ. 95 (2010) 270-278

[25] P.R. Gogate, M. Sivakumar, A.B. Pandit, Destruction of Rhodamine B using novel sonochemical reactor with capacity of 7.5 L, Sep. Purif. Technol. 34 (2004) 13-24.

[26] K. Dutta, S. Mukhopadhyaya, S. Bhattacharjee, B. Chaudhuri, Chemical oxidation of methylene blue using a Fenton-like reaction, J. Hazard. Mater. B 84 (2001) 57-71.

[27] A.M.F.M. Guedes, L.M.P. Madeiraa, R.A.R. Boaventuraa, C.A.V. Costaa, Fenton oxidation of cork cooking wastewater overall kinetic analysis, Water Res. 37 (2003) 3061-3069.

[28] C. Catrinescu, C. Teodosiu, M. Macoveanu, J. Miehe-Brende, R.L. Dred, Catalytic wet peroxide oxidation of phenol over Fe-exchanged pillared beidellite, Water Res. 37 (2003) 1154-1160.

[29] I. Arslan, I.A. Balcıoğlu, D.W. Bahneman, Advanced chemical oxidation of reactive dyes in simulated dyehouse effluents by ferrioxalate-Fenton/UV-A and $\mathrm{TiO}_{2} /$ UV-A processes, Dyes Pigments 47 (2000) 207-218.

[30] L. Nunez, J.A. Garcia-Hortal, F. Torrades, Study of kinetic parameters related to decolourization and mineralization of reactive dyes from textile dyeing using Fenton and photo-Fenton processes, Dyes Pigments 75 (2007) 647652.

[31] J. Fan, Y. Guo, J. Wang, M. Fan, Rapid decolorization of azo dye methyl Orange in aqueous solution by nanoscale zerovalent iron particles, J. Hazard. Mater. 166 (2009) 904-910.

[32] H.Xu, D. Zhang, W. Xu, Monitoring of decolorization kinetics of reactive brilliant blue X-BR by aniline spectrophotometric method in Fenton oxidation process, J. Hazard. Mater. 158 (2008) 445-453. 